\title{
Analysis on the Current Situation and Countermeasures of Rural Financial Services in China
}

\author{
Ke Haiqian \\ Nanyang Institute of Technology, Nanyang, Henan, 473000
}

Keywords: New Rural Construction, Rural Financial Services, Problem Analysis

\begin{abstract}
The construction of new socialist countryside needs a lot of financial support. The development and improvement of rural financial service industry is an important way to provide necessary funds for new rural construction. But in the actual situation, funds in many rural financial institutions will be siphoned off, to enter the capital of non-agriculture industry, leading to a serious imbalance between supply and demand of rural financial services, which not only restricts the development of rural economy, but the development of rural financial services. This paper expounds the connotation and characteristics of rural financial services, analyzes the existing problems of rural financial services at present stage, and puts forward specific solutions, so as to provide a reference for promoting the development of rural financial services in China.
\end{abstract}

\section{The meaning and characteristics of rural financial services in China}

Financial services refer to financial institutions that use monetary means to integrate valuable items and provide various beneficiaries to the participants in financial activities. Our financial system has gone through decades of development and reform, rural financial services including financial institutions of various commercial, policy and cooperative types, such as the Agricultural Bank, rural credit cooperatives, agricultural development Chinese milk line, the postal savings bank and some other new rural financial institutions and so on [1]. Among them, commercial banks as the main body of rural financial services, rural credit cooperatives as the core, and private lending as supplement, with agriculture, farmers and rural construction as the main service objects, has played an important role in promoting agricultural economic development. Compared with the traditional urban financial services, the rural financial services reflect the following characteristics:

First, it is periodic. Rural financial services mainly to agricultural production, and agricultural production activities has a strong cyclical cycle, income and expenditure of large span, the prices of agricultural products will be dramatic fluctuations, so the agricultural producers relied more on production of financing, the rural financial services also reflects the cyclical characteristics, increase financing risk [2]. Second, the diversity of the needs of the service objects. Rural financial services to farmers and rural enterprises as the main object, but different farmers and rural enterprises of the nature, content and production scale are quite different, so the different service object demand for financial services but also reflects the characteristics of multi-level, meet the demand of the financial means are different. Finally, the main body of supply and demand of credit funds is asymmetrical [3]. At present, the rural financial support to self-less funds of rural credit cooperatives, and grassroots credit cooperatives in order to reduce the credit risk, the financial business mainly to short-term loan; on the other hand, credit cooperatives to township enterprises put in the loan has become the main source of grassroots credit cooperatives do not suit the credit asset, so the characteristics of credit funds demand the asymmetry is very prominent.

\section{Problems Existing in Rural Financial Services in China}

In the process of rural economic development, there are still several problems in the rural financial services. 


\subsection{The rural financial service system is not perfect}

After years of development, China's rural financial system structure has been more and more diversified, including policy finance, commercial finance, cooperative finance and so on. But the existing financial service system whether the number of agencies, or types of services, compared with the variety of the rural market, the diversity of the main body of rural economic development, China's rural financial service system also has serious problems, not only conducive to the development of the rural economy, the financial products and service supply will restrict. For example, policy finance lacks breadth and depth and commercial financial level is single. Cooperative finance needs to be standardized. Especially, the number of rural small and medium-sized financial institutions is seriously insufficient, so it is impossible to form effective competitive market [4-5]. In addition, the rural investment environment, credit environment, financial infrastructure service facilities, policy guarantee mechanism and other financial services hardware conditions need to be improved.

\subsection{A single financial service product and a serious shortage of service institutions}

On the one hand, the difference of economic development of our country city and countryside is huge, a direct result of China's rural financial products in the city compared to the single problem, such as the rural financial services mainly deposits, withdrawals, loans and other business simple, can not meet the farmers' demand for diversified financial services. Farmers are the main body of rural financial services. With the continuous improvement of farmers' life and the change of life concept, the traditional rural financial services can not meet the actual needs of farmers. At present, the level of rural insurance in rural areas is uneven, and the local financial strength determines its service level [6]. The financial situation of the majority of rural areas is not optimistic, unable to meet the funding needs of agricultural production and operation organizations, especially the agricultural insurance catastrophe risk insurance, reinsurance and catastrophe risk reserve system is the main means to transfer and disperse the risk, national policy, financial and institutional support is weak. On the other hand, although the coverage of China more and more rural financial services institutions, but most of the financial authority can only handle single access business models, even unable to undertake small credit loans; commercial and financial institutions operating the final purpose is to maximize profits, the weak rural market to reduce rural credit the proportion of the service, to this kind of financial institutions more and more marginalized [7].

\subsection{Poor rural financial service environment}

Influenced by traditional concepts and farmers' overall quality, China's rural financial service environment is still in a relatively bad state, mainly in the following aspects: first, farmers' credit consciousness needs to be improved. The overall education level of the rural area is relatively low, and the comprehensive quality of the farmers is also low. Many farmers either fail to repay the loans on time or do not repay the loans, which has a very bad impact on the credit reputation of rural loans. Secondly, the investigation mechanism of rural loan needs to be improved [8]. At present, if farmers need loans, they only need to prove a family income certificate for the lender. Such a simple survey of lenders' income will easily lead to the lenders' loans, which will affect the overall credibility of the lender. Thirdly, the lack of financial services intermediaries in rural areas, many rural financial institutions because of the lack of third party guarantees affect their enthusiasm for loans, but also increased farmers' enthusiasm for loans. Finally, the state's guidance for rural financial institutions only stays at the policy level, and lacks substantive effective measures, which leads to the low enthusiasm of financial institutions.

\section{Strategies to Promote the Development of Rural Financial Services}

In view of the problems existing in rural financial services in China, it is suggested that the following aspects should be improved in order to promote the development of rural financial services. 


\subsection{Increasing the number of rural financial service institutions and enriching the products of financial services}

According to the needs of the development of rural economy, new rural financial services institutions are constantly being added to enrich financial services products, so as to promote the better development of rural financial services. First, improve the distribution density of rural financial institutions. The degree of development of city finance will have a direct impact on the financial services in rural areas, such as Beijing, Shanghai and other big city rapid financial development, the rural financial development is relatively fast; the development of the financial industry is slow the city, the development of rural financial industry also slightly lag, therefore it is necessary to expand the distribution density of rural financial institutions. Secondly, face the regional differences of rural financial services, rationally allocate and develop rural financial machinery rights, adjust the operation mode of financial services institutions according to the actual development of financial institutions in different regions. The characteristics of modern agricultural management of scale and industrialization, the scale of financial services to the "long" and "large" and "focus" in the direction of development, the way of service to expand from the traditional agricultural production and all aspects of the industry chain and value chain, extending to insurance, futures, securities etc. In addition, we must further develop information and networking financial services, and provide all round and networked information services to modern agricultural operators through the Internet electronic information platform [9-10]. The development of agricultural insurance premium subsidies, the implementation of the service function; re positioning of the Agricultural Development Bank, agricultural bank, strengthen policy coordination, business of financial cooperation; the organic combination of voluntary insurance and compulsory insurance, the establishment of agricultural catastrophe risk fund and agricultural insurance mechanism, so as to improve the status of rural financial services in china.

\subsection{Rational allocation of rural financial loan business}

China's rural financial market is still in the stage of exploration and growth. Aiming at the existing problems of rural financial services at present stage, we should rationally allocate the deposit and loan businesses of rural financial businesses, and establish a virtuous circle mechanism to guarantee savings and loan funds. First of all, we should build the financial investment mechanism of the capital circulation. Government departments should increase investment funds expenditure for agriculture, increase the proportion of financial funds in total expenditure, gradually formed a stable growth of the national agriculture funds management mechanism; clear the direction of investment of financial support for agriculture, to determine the capital investment focus, to promote rural economic development. Secondly, the construction of capital circulation credit investment mechanism. In the rural financial system, credit business plays a prominent role, which is the key to the development of rural finance, the agricultural policy bank government direct investment, policy oriented functions into full play, to increase agricultural construction support, and ultimately promote the development of rural economy. Finally, the guidance mechanism of capital circulation is constructed [11-12]. At present, China's rural finance is mainly dependent on the support of the government. However, the financial and policy credit funds that the government can provide is limited, which cannot solve the problem of rural capital shortage from the root, so we must play the guiding role of the policy. Through the economic means such as guarantee, tax and other economic means, we should build a guiding incentive mechanism to promote more social capital flows to agriculture and rural areas, and gradually develop it into a main channel to return funds to the countryside.

\subsection{Strengthening the infrastructure of rural financial services}

First of all, the construction of rural financial services infrastructure is in a weak link. Therefore, we need to upgrade the financial infrastructure in rural areas, build standardized institutions in rural areas, and improve the coverage of all kinds of electronic equipment. The promotion of the scientific and technological level of financial services in rural areas is promoted by the promotion 
of telephone POS system and self-help access equipment. Secondly, we should strengthen the training of financial institutions, cooperate with professional training institutions, guide the development of financial and rural institutions in a standardized way, comprehensively improve the comprehensive quality of rural financial institutions, and improve the quality of credit services. Thirdly, we should increase the cultivation of honesty culture in rural areas and improve the rural credit environment. The government should introduce a series of integrity management policies to clear up policy barriers. The financial institutions in the rural areas should unite to establish a credit information database and information sharing platform, and upgrade the banking institutions' service system through proper financial support, so as to give full play to the positive role of the credit registration and consultation system. Finally, we should further improve the positive incentive of credit and the mechanism of reverse discipline. The application of law, publicity, public opinion supervision and other means to establish credit mechanism covering extensive area of rural enterprises, credit rating and financial credit environment in rural areas to evaluate, guide and encourage all kinds of capital into the rural financial market, to create a good faith, credit good social atmosphere.

\section{Conclusions}

In short, with the continuous development of the rural economy and the deepening of the new rural construction, the level of rural financial services should also improve continuously, so that we can better serve the development of rural economy. Of course, there are still many problems in the rural financial service system at present. Government departments must achieve the sustainable development of rural financial institutions through reasonable guidance and support.

\section{References}

[1] Qu B, Li X, Liu J, et al. Analysis of the current situation regarding the aging rural population in China and proposed countermeasures[J]. Population Health Management, 2012, 15(3):181.

[2] Zhang, Caili, Shoujin, et al. Current Situation and Countermeasures of Water Body Pollution in Rural Areas of China [J]. Research on Meteorology and Environment: English Edition, 2015, 63(1):42-47.

[3] Niu Q. Current Situation of and Countermeasures for the Development of Rural Informatization in China [J]. Studies in Sociology of Science, 2014, 5(4).

[4] Hou M, Chen W, Yang Z. Current situation and countermeasures of strategic emerging industries in China[C]// International Conference on Services Science and Services Information Technology. 2014:461-466.

[5] Chen X H. Analysis of the Present Situation and Countermeasures of the Door to Door Railway Freight Service in China [J]. Logistics Engineering \& Management, 2016.

[6] Zhao W J, Ding F L. A Review on the Current Situation and Countermeasures of Water-saving Irrigation Technology Extension in China [J]. Water Saving Irrigation, 2015.

[7] Huang X, Zhu L, Peng B, et al. Research on the Present Situation and Countermeasures of New Rural Cooperative Medical Insurance in Western China-Take Sichuan Province as an Example[J]. Medicine \& Jurisprudence, 2014.

[8] Dong J. Present Situation, Problems and Countermeasures of the Development of Green Finance in China [J]. Journal of Industrial Technological Economics, 2013.

[9] Du L Z, Chen X, Sun X M, et al. Analysis on Current Situation and Countermeasures of Rural Household Garbage in China [J]. Advanced Materials Research, 2014, 955-959:2640-2643.

[10] Zhang Z P, Sheng Y, Guo Y. The Development of Rural Mutual Cooperatives in China: Current Status, Existing Problems and Its Countermeasures[C]// International Conference on E-Business 
and E-Government. 2012:1169-1173.

[11] Zhang H, Zheng J, Chen J, et al. The current status and countermeasures of supervision ability on rural medical service in Fujian province [J]. China Health Law, 2015, 107:177-184.

[12] Dong L L, Ling Y U, Biochemistry D O, et al. Current Situation and Countermeasures of Rural Living Rubbish in China[J]. Modern Agricultural Science \& Technology, 2013, 9(2):153-185. 